\title{
ЕВРОСОЮЗ И ТУРЦИЯ: РАЗЛИЧИЯ В «ЦЕНОСТЯХ» И ТРАКТОВКЕ СУВЕРЕНИТЕТА
}

Аннотация. В статье рассматриваются причины усиливающейся напряжённости между Туриией и Евросоюзом. В конце мая 2019 г. рабочие структуры Еврокомиссии констатировали, что переговоры с Анкарой о вступлении страны в ЕС зашли в тупик. Основное внимание в статье уделяется двум группам факторов: первая связана с оценками европейцев ужесточения авторитарного режима в Турции; вторая - с военными операчиями Анкары на территории северной Сирии. Подробно рассматривается обострившаяся для Анкары проблема с поставками российской зенитно-ракетной системы (ЗРС) C-400. Автор приходит к выводу, что России следует быть готовой к любому развороту событий вокруг ЗРС, делая ставку на долгосрочные экономические проекты взаимодействия с Туричий.

Ключевые слова: Туриия, Евросоюз, беженць, С-400, Сирия, курды, США, Европарламент, Пэтриот, Россия.

Евросоюз, сохраняющий двери открытыми для вступления Турции, неизменно уделяет повышенное внимание выполнению Анкарой ряда требований, связанных с утверждением верховенства закона и соблюдением фундаментальных прав человека. Серьёзные претензии были адресованы Европарламентом турецким властям ещё в июне 2013 г. в связи с репрессиями последних в отношении участников массовых митингов протеста в центре Стамбула ${ }^{1}$. Анкара пошла на обострение отношений, отвергнув позицию европарламентариев и обвинив их в «безответственности». Глава турецкого МИД Эгемен Баджис, в свою очередь, заявил, что его страна «имеет самое сильное и реформистски настроенное правительство в Европе, а также самого сильного и харизматичного лидера в мире» ${ }^{2}$.

Следующая волна критики ЕС обрушилась на Анкару из-за репрессий окружения Эрдогана в отношении подозреваемых в причастности к провалившемуся путчу в июле 2016 г. $^{3}$ Тогда в тюрьмах оказались свыше сотни тысяч людей из числа военных, гражданских активистов, чиновников, судей, профессоров и журналистов. За этим последовал референдум 2017 г. по изменению турецкой конституции, в результате которого в руках президента концентрировалась большая часть властных полномочий, что ослабило систему политических сдержек и противовесов. В документах Еврокомиссии конца мая 2019 г. подчёркивается, что

(C) Шумилин Александр Иванович - доктор политических наук, главный научный сотрудник Отдела европейской безопасности, руководитель Центра «Европа - Ближний Восток» ИЕ РАН. Адрес: 125009, Россия, Москва, ул. Моховая 11-3. E-mail: mideast@ mail.ru.

DOI: http://dx.doi.org/10.15211/vestnikieran320197681

${ }^{1}$ European Parliament resolution of 13 June 2013 on the situation in Turkey (2013/2664(RSP). European Parliament, 13.06.2013. URL: https://www.europarl.europa.eu/sides/getDoc.do?type=TA\&reference=P7-TA-2013-0277\&language =EN (дата обращения: 09.06.2019).

2 Batalla L. EU-Turkey relations after Gezi: another halt or an incentive to revive Turkey's moribund accession process? UPA, July 2013. URL: http://politikaakademisi.org/2013/07/15/eu-turkey-relations-after-gezi-another-halt-or-anincentive-to-revive-turkeys-moribund-accession-process/ (дата обращения: 09.06.2019).

${ }^{3}$ Kingsley P., Rankin J. Europe and US urge Turkey to respect rule of law after failed coup. The Guardian, 18.07.2016. URL: $\quad$ https://www.theguardian.com/world/2016/jul/18/european-leaders-urge-turkey-to-respect-rule-of-law-afterfailed-coup (дата обращения: 08.06.2019). 
Турция «всё заметнее отдаляется от ценностей Евросоюза, который ставит во главу угла верховенство закона и соблюдение фундаментальных прав человека» ${ }^{1}$. При этом в упомянутом документе отмечается, что Турция остаётся ключевым партнером для ЕС и сохраняет статус страны-кандидата.

\section{Испытание сирийским кризисом}

Целый ряд внутренних проблем, повлиявших на отношения Турции с Европейским союзом, обострились из-за сирийского кризиса. Одну из них - проблему сирийских беженцев - Анкаре удалось смягчить во взаимодействии с европейцами. Так, после серии переговоров в 2015-2016 гг. Брюссель и Анкара достигли компромисса по размещению беженцев (главным образом из Сирии в лагерях на территории Турции при финансовой поддержке Евросоюза) $)^{2}$. Однако вскоре озабоченность ЕС вызвали последовательно развёрнутые Турцией две военные операции на севере Сирии («Щит Евфрата» в 2016-2017 гг. и «Оливковая ветвь»проводится с января 2018 г. по настоящее время), изначально преследовавшие цель не столько вытеснить террористов «Исламского государства» (ИГ), сколько нейтрализовать курдские формирования, союзников Международной коалиции против ИГ.

Эта озабоченность периодически оглашается как на уровне ЕС, так и лидерами ведущих европейских государств ${ }^{3}$. В их заявлениях делается акцент на неприемлемости жертв среди мирных курдов в Сирии, а также на несоответствии этих операций задачам борьбы с террористическими группировками. Кроме того, военные действия Анкары подрывают, с точки зрения Европейского союза, так называемый «большой политический процесс примирения» между турками и курдами, который при активном содействии ЕС был начат тогдашним главой турецкого правительства Р.Т. Эрдоганом и находившимся в заключении лидером Курдской рабочей партии (КРП) Абдуллой Оджаланом. Целью этого процесса провозглашалось достижение соглашения о переходе КРП от военных средств к политическим и в установлении механизмов, обеспечивающих равноправное сосуществование турок и курдов в рамках одного государства ${ }^{4}$.

Действия Турции в Сирии руководство ЕС называет «односторонними», понимая под этим отход Анкары от скоординированной стратегии коалиции против ИГ. Между тем это вполне, на наш взгляд, можно назвать частным случаем более общего «отхода/отклонения» Турции от курса на стратегическое взаимодействие с Евросоюзом. Его политико-институциональной основой, судя по всему, служит партийная коалиция под названием «Народный альянс» в составе правящей Партии справедливости и развития (ПСР - лидер Р.Т. Эрдоган) и националистической Партии национального движения (ПНД - лидер Д. Бахчели). По мнению известного тюрколога, сотрудника Фонда Карнеги Марка Пьерини, «альянс ПСР и ПНД подвиг руководство страны к ужесточению его антизападного нарратива, особенно по отношению к США и в несколько меньшей степени - к Европе» 5 .

\footnotetext{
1 Turkey 2019 Report. European Commission, Brussels, 29.05.2019. URL: https://ec.europa.eu/neighbourhoodenlargement/sites/near/files/20190529-turkey-report.pdf (дата обращения: 09.06.2019).

${ }_{2}^{2}$ Кузнецов А., Макаренко Г. ЕС и Турция заключили сделку по беженцам. РБК, 18.03.2019. URL: https:// www.rbc.ru/politics/18/03/2016/56ec16f99a7947220d76f900 (дата обращения: 29.05.2019).

${ }^{3}$ EU committee drafts bill addressing human rights violations in Afrin. Rudaw Media, 21.02.2019. URL: http://www. rudaw.net/english/middleeast/turkey/21022019 (дата обращения: 29.05.2019).

${ }^{4}$ Оджалан призвал курдов положить конец конфликту с Турцией. РИА Новости, 21.03.2013. URL: https://ria.ru/ 20130321/928413177.html (дата обращения: 28.05.2019).

5 Pierini M. Options for the EU-Turkey Relationship. Carnegie Europe, 03.05.2019. URL: https://carnegieeurope. eu/2019/05/03/options-for-eu-turkey-relationship-pub-79061 (дата обращения: 28.05.2019).
}

Научно-аналитический вестник ИЕ РАН, 2019, №3 


\section{Российские С-400 против американских «Пэтриот»}

Сочетание этого внутриполитического фактора с нараставшей вовлечённостью Турции в военные операции на территории Сирии обусловили ещё один феномен, усиливший раздражение в отношениях между Анкарой, с одной стороны, Вашингтоном и Брюсселем - с другой. Речь о завершении в июле 2018 г. переговоров и подписании контракта с Россией на поставки четырёх батарей зенитно-ракетных систем (ЗРС) C-400. Это решение турецкого руководства вызвало резко отрицательную реакцию прежде всего со стороны Вашингтона и Североатлантического альянса ${ }^{1}$. Основанием же для столь «скандального» для страны - члена НАТО поворота (по сути отхода от обязательств придерживаться натовских стандартов в вооружениях особенно стратегического характера) стали, на наш взгляд, два важных для Турции фактора:

- вывод Соединёнными Штатами и Германией с территории Турции значительного числа размещавшихся там с 2013 г. соответственно американских и германских батарей ЗРС «Пэтриот» (формально для «нейтрализации ракетных угроз с территории Сирии»), и это - в период наивысшего обострения противостояния между Турцией и Россией (конец 2015 - начало 2016 гг.). Можно предположить, что тем самым Вашингтон и Берлин стремились избежать вовлечённости в конфликт с Россией в случае нанесения российскими ВВС «непреднамеренных» ударов по упомянутым ЗРС; командование НАТО предложило вместо ЗРС направить в Турцию самолёты и корабли для «обеспечения патрулирования» границ своего союзника; показательно также, что вскоре после вывода своих ЗРС США предложили Турции купить у них те же системы «Пэтриот» ${ }^{2}$;

- примирение с Россией во второй половине 2016 г. (после сбития российского бомбардировщика в конце 2015 г.), происходившее на фоне осложнения отношений с США (провал попытки военного переворота в Турции, отказ Вашингтона выдать Анкаре скрывающегося в США проповедника Фетхуллаха Гюлена); усиление продуктивного (с точки зрения Эрдогана) взаимодействия с Россией по широкому спектру проблем, касавшихся курдов.

Во многом именно эти события - вкупе с более выгодными условиями продажи и поставок ЗРС в сравнении с американскими «Пэтриот», а именно, 2,5 млрд долл. вместо 3,5 млрд соответственно - подтолкнули турецкое руководство внимательно рассмотреть российские предложения по поставкам ЗРС С-400. Поначалу, считает авторитетный турецкий эксперт Синан Ульген, окружение Эрдогана пыталось использовать предложенную Россией сделку по C-400 как инструмент давления на США с целью выторговать более благоприятные условия по ЗРС «Пэтриот» ${ }^{3}$. Но не только в вопросе ЗРС, судя по всему, рассчитывал Эрдоган таким образом получить уступки администрации Трампа. Другой задачей, считает тот же С. Ульген, было побудить Вашингтон отказаться от поддержки тех курдских группировок в Сирии (в частности, «Силы защиты курдского народа» - аббревиатура по-английски YPG), которые Анкара считала аффилированными с Курдской рабочей партией, определённой Анкарой, Брюсселем и Вашингтоном в качестве «террористической организации» ${ }^{4}$. И, судя по всему, в опре-

\footnotetext{
${ }^{1}$ US' Pence: Turkey must choose between S-400, NATO. MEMO, 03.04.2019. URL: https://www.middleeastmonitor. com/20190403-us-pence-turkey-must-choose-between-s-400-nato (дата обращения: 26.05.2019).

${ }^{2}$ Bekdil B. US Begins Removing Patriot Missiles from Turkey. Defence News, 11.10.2015. URL: https://www.de fensenews.com/home/2015/10/11/us-begins-removing-patriot-missiles-from-turkey/ (дата обращения: 27.05.2019); Bekdil B. Germany Pulls Patriot Systems From Turkey. Defence News, 23.12.2015. URL: https://www.defensenews. com/home/2015/12/23/germany-pulls-patriot-systems-from-turkey/ (дата обращения: 27.05.2019).

${ }^{3}$ Ulgen S. It's Not Too Late to Stop Turkey From Realigning With Russia. Foreign Policy, 11.04.2019. URL: https:// foreignpolicy.com/2019/04/11/its-not-too-late-to-stop-turkey-from-realigning-with-russia-s400-patriot-missile-putinerdogan-trump/ (дата обращения: 29.05.2019).

${ }^{4}$ Там же.
}

Научно-аналитический вестник ИЕ РАН, 2019, №3 
делённый момент это давление Анкары дало результаты: 19 декабря 2018 г. после телефонного разговора с Эрдоганом Трамп объявил о своём решении вывести американские подразделения из северных районов Сирии, переложив на Турцию задачи проведения дальнейших операций по обеспечению безопасности там. Это означало де-факто, что Анкара получала картбланш на устранение всех курдских группировок, которые она определяла как враждебные. Данное решение Трампа вызвало протесты высшего эшелона военного истеблишмента (часть генералов во главе с министром обороны Джеймсом Мэттисом подали в отставку), групп конгрессменов в Вашингтоне, союзников США в регионе, а также большинства руководителей государств Евросоюза ${ }^{1}$. Подчеркнём, что политический истеблишмент ЕС в намного большей степени, чем американский, проявляет озабоченность состоянием курдской проблемы, трактуя её как гуманитарную и правозащитную, а также критикует действия Турции в отношении курдов, в частности. При этом Евросоюз выступает против создания независимого курдского государства и против курдского сепаратизма в целом².

В конечном счете декабрьское 2018 г. жёсткое заявление Трампа о выводе войск из Сирии было смягчено усилиями советника по национальной безопасности Джона Болтона: ему удалось достичь договорённости с партнёрами по антитеррористической коалиции о постепенном выводе большей части из 2000 американских военнослужащих в Сирии «в зависимости от конкретных обстоятельств» при сохранении там не менее 400 военнослужащих при условии, что европейцы увеличат свои контингенты ${ }^{3}$.

Этот поворот в политике Трампа вызвал разочарование Эрдогана, который продолжил «разыгрывать карту» С-400 в отношениях с Вашингтоном ${ }^{4}$. К весне 2019 г. эта проблема обострилась до стадии открытого противостояния между окружением Эрдогана, настаивавшем на своём суверенном праве решать вопрос о ЗРС, и командой Трампа, начавшей угрожать Турции применением санкций ${ }^{5}$.

Обращает на себя внимание тот факт, что на протяжении разворачивания скандала вокруг российских C-400 европейские политики старались держаться от него в стороне. Ясно, что они де-факто поручили генсеку НАТО выступать в том числе и от их имени, но сами в основном хранили молчание. Одно из объяснений этому даёт аналитик Файсал аль-Яфаи. В частности, в газете Asia Times под заголовком «Наибольший ущерб от американо-турецкого спора понесёт Евросоюз» он пишет следующее: «Этот спор имеет серьёзные последствия для Евросоюза. Он рискует расколоть альянс, который является гарантией безопасности Европы, выталкивая кардинально важного союзника из НАТО в объятия России. Поэтому, несмотря на свою обоснованную нелюбовь к Дональду Трампу и Реджепу Эрдогану, для европейцев жизненно важно стать посредниками в урегулировании этого спора» 6 .

Тот факт, что Турция всё активнее заявляет о своих национальных интересах, часто противоречащих интересам европейцев, объясняет крайне низкий уровень её взаимодействия с

\footnotetext{
1 Syria conflict: Trump's withdrawal plan shocks allies. BBC News, 20.12.2018. URL: https://www.bbc.com/ news/world-us-canada-46628811 (дата обращения: 29.05.2019).

${ }^{2}$ EU against «Kurdish separatist agenda»: Mogherini. Anadolu Agency, 24.02.2016. URL: http://www.turkiyenewspa per.com/world/8583.aspx (дата обращения: 29.05.2019).

Syria conflict: Bolton says US withdrawal is conditional. BBC News, 06.01.2019. URL: https://www.bbc.com/ news/world-us-canada-46775308 (дата обращения: 30.05.2019).

${ }^{4}$ Bar'el Z. Erdogan Rejoiced at Trump's Syria Pullout. Then He Realized It Was Trump. Haaretz, 10.01.2019. URL: https://www.haaretz.com/middle-east-news/syria/.premium-with-u-s-exit-from-syria-unraveling-erdogan-faces-seriousdilemma-1.6824953 (дата обращения: 30.05.2019).

5 Bellut D. US threatens to impose sanctions on NATO ally Turkey. DW, 24.05.2019. URL: https://www.dw.com/ en/us-threatens-to-impose-sanctions-on-nato-ally-turkey/a-48870369 (дата обращения: 29.05.2019).

${ }^{5}$ Al Yafai F. Biggest loser from US-Turkey defense spat will be EU. Asia Times, 29.04.2019. URL: https://www.asia times.com/2019/04/opinion/biggest-loser-from-us-turkey-defense-spat-will-be-eu/ (дата обращения: 30.05.2019).
}

Научно-аналитический вестник ИЕ РАН, 2019, №3 
Брюсселем. Французский президент считается одним из европейских лидеров, который хочет положить конец двойственности в отношениях Турции и ЕС. «Надо избавляться от лицемерия, предусматривающего мысль о возможности открыть новые главы на переговорах (Турции - А.Ш.) с Евросоюзом, это неправда», - сказал Эммануэль Макрон в 2018 г., призвав Анкару «уважать верховенство закона» ${ }^{1}$. При этом Макрон предложил Эрдогану альтернативу членства Турции в ЕС в виде «расширенного сотрудничества» и «партнёрства»². В этом контексте не удивляет, что 13 марта 2019 г. Европарламент большинством голосов высказался за приостановление переговоров о вступлении Турции в Евросоюз ${ }^{3}$.

\section{Выводы}

Негативный тренд в отношениях между Анкарой и Брюсселем стимулируется главным образом нарастающими проблемами в Турции, которые развиваются по замкнутому кругу: массовые протесты социально-экономического характера в крупных городах провоцируют репрессии со стороны властей, подталкивают их к ужесточению «авторитарно-персоналистского режима» Р.Т. Эрдогана, что вызывает отрицательную реакцию со стороны ЕС; и наоборот усиливающаяся критика поведения турецких властей со стороны ЕС объективно стимулирует недовольство населения этой страны в первую очередь своим правительством и во вторую очередь - Евросоюзом. Попытки Эрдогана переключить внимание части своего населения на противостояние внешней угрозе в Сирии через противодействие вооруженным курдским группировкам также вызывают критическую оценку со стороны европейского истеблишмента.

В удержании пошатнувшегося баланса в отношениях Анкары с Брюсселем, во многом опирающихся на ценностные параметры (верховенство закона, права человека), турецкому руководству время от времени «подыгрывает» администрация Дональда Трампа, подчёркивая важность взаимодействия с Турцией в военно-стратегическом плане. Именно в этом ключе следует рассматривать заявленное Трампом в декабре 2018 г. намерение вывести американских военнослужащих из Сирии, возложив на Турцию обязательства по поддержанию безопасности в северо-восточных районах там. Однако платой за готовность Трампа поддерживать Эрдогана должен стать отказ Анкары от договорённостей с Москвой по С-400. Для европейцев вопрос о приобретении Турцией российских ЗРК не стоит столь остро, как для США, поскольку для них на фоне временного блокирования процесса вступления Турции в ЕС важно как минимум сохранить эту страну в составе НАТО, не допустить её разворота к России. Турция была и остаётся для Евросоюза страной, призванной минимизировать угрозы с Ближнего Востока, а также отчасти и от России.

Обострившееся противостояние между Анкарой и её западными партнёрами обозначило пределы в проводившейся в последние годы Эрдоганом политике балансирования на внешнем контуре (между ЕС и Россией) для усиления его позиций внутри страны. Немалая часть турецких элит, по имеющимся сведениям, не готова к дальнейшему осложнению отношений с Западом. К тому же Эрдоган, со своей стороны, похоже, исчерпал возможности использова ния российского фактора в качестве инструмента давления на союзников по НАТО. В этой ситуации, на наш взгляд, со стороны турецкого руководства следует ожидать скорее шагов в направлении снижения напряжённости с Западом, чем сближения с Россией. Москве надо

\footnotetext{
${ }^{1}$ Там же.

2 Macron ferme la porte à une adhésion de la Turquie dans l'UE. Le Point International, 05.01.2018. URL: https:// www.lepoint.fr/monde/erdogan-a-paris-une-visite-sous-le-sceau-du-pragmatisme-05-01-2018-2184148_24.php (дата обращения: 09.06.2019).

${ }^{3}$ Reilhac G. EU parliament calls for freeze on Turkey's membership talks. Reuters, 13.03.2019. URL: https://www. reuters.com/article/us-eu-turkey/eu-parliament-calls-for-freeze-on-turkeys-membership-talks-idUSKCN1QU2LD (дата обращения: 30.05.2019).
}

Научно-аналитический вестник ИЕ РАН, 2019, №3 
быть готовой к любому варианту окончательного решения Анкары по C-400, делая ставку на развитие таких стратегических проектов взаимодействия с Турцией в сфере экономики, как «Турецкий поток» и строительство к 2023 г. атомной электростанции «Аккую».

\section{References}

Batalla L. EU-Turkey relations after Gezi: another halt or an incentive to revive Turkey's moribund accession process? UPA, July 2013. URL: http://politikaakademisi.org/2013/07/15/eu-turkeyrelations-after-gezi-another-halt-or-an-incentive-to-revive-turkeys-moribund-accession-process/.

Bekdil B. US Begins Removing Patriot Missiles from Turkey. Defence News, 11.10.2015. URL: https://www.defensenews.com/home/2015/10/11/us-begins-removing-patriot-missiles-from-turkey/.

Bekdil B. Germany Pulls Patriot Systems From Turkey. Defence News, 23.12.2015. URL: https://www.defensenews.com/home/2015/12/23/germany-pulls-patriot-systems-from-turkey/

European Parliament resolution of 13 June 2013 on the situation in Turkey (2013/2664(RSP)). European Parliament, 13.06.2013. URL: https://www.europarl.europa.eu/sides/getDoc.do?type=TA \&reference=P7-TA-2013-0277\&language $=\mathrm{EN}$.

EU committee drafts bill addressing human rights violations in Afrin. Rudaw Media, 21.02.2019. URL: http://www.rudaw.net/english/middleeast/turkey/21022019.

Pierini M. Options for the EU-Turkey Relationship. Carnegie Europe, 03.05.2019. URL: https://carnegieeurope.eu/2019/05/03/options-for-eu-turkey-relationship-pub-79061.

Reilhac G. EU parliament calls for freeze on Turkey's membership talks. Reuters, 13.03.2019. URL: https://www.reuters.com/article/us-eu-turkey/eu-parliament-calls-for-freeze-on-turkeys-mem bership-talks-idUSKCN1QU2LD.

Sloat A. The West's Turkey conundrum. The Brookings Institution, February 2018. P. 5. URL: https://www.brookings.edu/wp-content/uploads/2018/02/fp_20180212_west_turkey_conundrum.pdf.

Turkey 2019 Report. European Commission, Brussels, 29.05.2019. URL: https://ec.europa.eu/ neighbourhood-enlargement/sites/near/files/20190529-turkey-report.pdf.

\section{EU and Turkey: Disagree on «Values» and Interpretation of Sovereignty}

Author. Alexander Shumilin, Doctor of Sciences (Politics), Chief Research Associate, European Security Department, Institute of Europe, Russian Academy of Sciences. Address: 11-3, Mokhovaya str., Moscow, Russia, 125009. E-mail: mideast@mail.ru.

Annotation. The paper is focused on the causes of the growing tension between Ankara and Brussels with the impasse in the Turkey's adherence negotiations. The author examines two groups of factors: the first is related to the Europeans' estimations of the escalation of the authoritarian nature of the ruling regime in Ankara; the second is to do with the Turkey's military operations in Northern Syria. The author explores the escalated issue for Ankara resulted from the contract with Russia pertaining to deliveries of the Russian S-400 systems. The main point of the study is that Russia should be prepared to any outcome over the S-400 deal while emphasizing the long term contracts of economic cooperation with Turkey like the Turkish gas stream and nuclear station construction.

Keywords: Turkey, European Union, refugees, S-400, Syria, Kurds, Russia

DOI: http://dx.doi.org/10.15211/vestnikieran320197681 